\title{
Improving the mucosal visualization at gastroscopy: a systematic review and meta-analysis of randomized, controlled trials reporting the role of Simethicone $\pm \mathbf{N}$-acetylcysteine
}

\author{
Muhammad Shafique Sajid ${ }^{1}$, Saad Rehman ${ }^{1}$, Fergus Chedgy ${ }^{2}$, Krishna K. Singh ${ }^{3}$ \\ ${ }^{1}$ Department of General and Colorectal Surgery, ${ }^{2}$ Department of Gastroenterology \& Hepatology, ${ }^{3}$ Department of General and Upper GI Surgery, \\ Brighton \& Sussex University Hospitals NHS Trust, The Royal Sussex County Hospital, Brighton, UK \\ Contributions: (I) Conception and design: MS Sajid; (II) Administrative support: S Rehman, KK Singh; (III) Provision of study materials or patients: \\ MS Sajid, F Chedgy, S Rehman; (IV) Collection and assembly of data: S Rehman, F Chedgy; (V) Data analysis and interpretation: MS Sajid, KK \\ Singh; (VI) Manuscript writing: All authors; (VII) Final approval of manuscript: All authors. \\ Correspondence to: Mr Muhammad Shafique Sajid. Consultant Gastrointestinal Surgeon, Department of Gastrointestinal Surgery, Brighton and Sussex \\ University Hospitals NHS Foundation Trust, Eastern Road, Brighton, East Sussex, BN2 5BE, UK. Email: surgeon1wrh@hotmail.com.
}

\begin{abstract}
Background: The objective of this article is to study the role of Simethicone $\pm \mathrm{N}$-acetylcysteine in improving the mucosal visualization during oesophago-gastro-duodenoscopy (OGD).

Methods: The data retrieved from the published randomized controlled trials (RCTs) reporting the role of Simethicone $\pm \mathrm{N}$-acetylcysteine during OGD was analysed using the principles of meta-analysis. The summated outcome of continuous variables was expressed as standardized mean difference (SMD) and dichotomous data was presented in odds ratio (OR).

Results: Three RCTs on 654 patients reported OGD with and without pre-procedure oral administration of Simethicone $\pm \mathrm{N}$-acetylcysteine evaluating visibility as good or excellent in number during the procedure. In the random effects model analysis using the statistical software Review Manager 5.3, the use of Simethicone $\pm \mathrm{N}$-acetylcysteine was associated with improved (OR, 0.43; 95\% CI, 0.28, 0.68; $\mathrm{z}=3.65$; $\mathrm{P}=0.0003$ ) mucosal visibility. Four RCTs on 364 patients reported OGD with and without pre-procedure oral administration of Simethicone $\pm \mathrm{N}$-acetylcysteine evaluating visibility score in study group. In the random effects model analysis using the statistical software Review Manager 5.3, the use of Simethicone \pm $\mathrm{N}$-acetylcysteine was associated with improved (SMD, -1.66; 95\% CI, -1.93, -1.40; z=12.25; P=0.00001) mucosal visibility score compared to no-Simethicone group.

Conclusions: The findings of current study on 1,099 patients successfully demonstrate that the preprocedure oral administration of Simethicone $\pm \mathrm{N}$-acetylcysteine improves mucosal visualization and mucosal visualization score during OGD.
\end{abstract}

Keywords: Oesophago-gastro-duodenoscopy (OGD); gastroscopy; mucosal visualization; mucus froth; mucous bubbles

Received: 29 April 2018; Accepted: 03 May 2018; Published: 19 May 2018.

doi: $10.21037 / \operatorname{tgh} .2018 .05 .02$

View this article at: http://dx.doi.org/10.21037/tgh.2018.05.02

\section{Introduction}

Oesophago-gastro-duodenoscopy (OGD) is an essential component in the diagnostic and management pathway for a variety of benign and malignant conditions of upper gastrointestinal tract (1). Thorough and adequate mucosal visualisation during OGD is an essential practice to accurately identify and characterise the lesions as part of disease diagnosis and surveillance. Endoscopic mucosal visibility is impaired by several factors including poor endoscopy technique, excessive mucus, residual food due to 
inadequate pre-procedure fasting, inadequate positioning and more importantly the presence of mucosal froth and bubbles in the oesophagus, stomach and duodenum. The froth and bubbles are made of mucous secretions mixed with gastric juice and bile. The aforementioned factors are potentially modifiable factors to improve mucosal visualization and avoid missed diagnoses. Various studies have demonstrated the incidence of missed diagnoses on upper gastrointestinal endoscopy and this could be prevented by efforts to improve mucosal visibility (2-6). Simethicone with or without $\mathrm{N}$-acetyl cysteine (NAC) is one of the most frequently used pre-procedural oral medication to counteract the poor mucosal visibility secondary to froth and bubbles. It has been shown effective in improving visibility in several studies and trials for adequate visualization of gastrointestinal tract like colonoscopy, capsule endoscopy and gastroscopy. The timing and dose of these agents varies between different studies (7-10). Simethicone and NAC are de-foaming and mucolytic agents respectively (11-14). They work by decreasing surface tension and breaking down the adhesive forces between molecules and cause dispersion of foam and mucous bubbles (11-14). These agents have also been shown to decrease amount of water needed to flush during endoscopy and improve mucosal visibility (15).

Recent data shows that around 7 in 10 stomach cancer cases are diagnosed at a late stage in the UK $(16,17)$. This depends on many factors, one of which would be an inability to pick up early lesions on upper GI endoscopy. Undoubtedly poor mucosal visualization due to froth and bubbles is also an influencing factor for poor diagnostic accuracy in these patients. The practice of taking preendoscopy drink is still not an established practice in the Europe partly because of lack of randomized control trials (RCTs). According to the UK wide survey in 2016, no NHS trust was using pre-OGD drinks to enhance mucosal visibility $(16,17)$. Current study is an attempt to systematically analyse published trials reporting the effectiveness of Simethicone \pm NAC in improving mucosal visualization during OGD including recently published 3 RCTs from Europe.

\section{Methods}

\section{Electronic data base search}

Medline (via PubMed), Embase, Scopus, Cochrane Upper Gastrointestinal and Pancreatic Diseases (UGPD)
Controlled Trial Register, the Cochrane Central Register of Controlled Trials (CENTRAL) in the Cochrane Library and Science Citation Index Expanded were explored until March 2018 to find relevant published RCTs. The search terms were constructed based on patients, interventions/ comparators, and outcomes as follows:

* Patients: undergoing OGD for the suspected but not limited to this diagnosis of gastric cancer, oesophageal cancer, reflux disease, peptic ulcer disease, pancreatic cancer, achalasia, gastric polyps, duodenal polyps and ampullary tumours;

* Intervention/comparator: oral administration of Simethicone \pm NAC as premedication drink before OGD;

* Outcomes: good mucosal visibility rate and mucosal visibility score.

The MeSH terms related to the suspected diagnosis of gastric cancer, oesophageal cancer, reflux disease, peptic ulcer disease, pancreatic cancer, achalasia, gastric polyps, duodenal polyps and ampullary tumours in conjunction with OGD were identified from the PubMed and subsequently inserted in the search boxes of other electronic databases. Attempts to find extra trials were also made by the hand searching of the references of published studies.

\section{Data management}

Three reviewers (MS Sajid, KK Singh and S Rehman) independently searched and selected studies and disagreements were resolved by mutual consensus. Inclusion criteria were as follows: RCT in patients with undergoing diagnostic OGD for any reason; patient using Simethicone \pm NAC as premedication just before the procedure; and had at least one outcomes of interest as described above. The studies were included regardless of sample size, origin of study, age of the participant, gender of the participant and the language in which the study was published.

\section{Interventions}

The intervention of interest was the use of oral preparation of Simethicone \pm NAC before OGD.

\section{Outcome of interest}

We studied outcomes good mucosal visibility rate and mucosal visibility score. We followed strict inclusion criteria and extracted the data from those published trials 
which reported either mucosal visibility score or number (n) of patients with good/excellent mucosal visibility during OGD. The adjustments were made to homogenise the data between trials in order to achieve combined statistical outcome such as published percentage was converted to exact numbers after mathematical calculations. If standard deviation was not reported in the published study, it was either estimated from the reported range value or $\mathrm{p}$-value. We excluded trials reporting bubble score, haziness score and amount of water flushing required in improving mucosal visibility due to insufficient and heterogeneous data.

\section{Risk of bias assessment}

The methodological quality of the included studies was assessed by MSS and SR as recommended by the Cochrane Collaboration using the "Risk of Bias Assessment Tool". This included random sequence generation, allocation concealment, blinding of participants and personnel, blinding of outcome assessment, incomplete outcome data, and selective outcome reporting. Disagreement was resolved by a third reviewer (SR). The critical appraisal tool to score the quality of included trials was also adopted from the published guidelines of Jadad et al. (18) and Chalmers et al. (19). The short summary of the resulting evidence was presented in a tabulated form by using tool GradePro ${ }^{\circledR}(20)$, provided by the Cochrane Collaboration.

\section{Statistical analysis}

The efficacy of Simethicone \pm NAC was directly compared and pooled for each outcome of interest if there were at least two studies for each comparison. For dichotomous data the odds ratio (OR) was estimated and pooled across studies using a random-effect model. For continuous data analysis standardized mean difference (SMD) was estimated and pooled across studies using a random-effect model. Heterogeneity was assessed using Cochrane $\mathrm{Q}$ test and $\mathrm{I}^{2}$ statistic. The statistical analysis of the data was conducted according to the guidelines provided by the Cochrane Collaboration including the use of RevMan $5.3^{\circledR}$ statistical software, and the use of forest plots for the graphical display of the combined outcomes (21-27).

\section{Results}

\section{Characteristics of selected trials}

A total of 171 studies were identified from Scopus, Medline and other electronic databases. Among them, 7 RCTs $(\mathrm{n}=1,099)$, published until March 2018, were eligible for inclusion (28-36); and the reasons for ineligibility are described in PRISMA flow chart Figure 1. The extracted data from the included trials is given in Tables 1 and 2.

\section{Risk of bias in selected studies}

Summary of the evidence analysed in the GRADE-Pro tool is given in Figure 2 denoting the high quality of evidence based upon outcomes as per protocol scoring systems. Among seven studies, 98\% were considered at low risk of bias due to the presence of random sequence generation, allocation concealment (selection bias), blinding of participants, blinding of outcome assessment (performance bias), data management (attribution bias), incomplete outcome data (detection bias) and selective outcome reporting (reporting bias).

\section{Mucosal visibility score}

Four RCTs (28-31) reported visibility score and contributed to the combined calculations of this variable. For this outcome measure, a statistically significant heterogeneity $\left[\mathrm{Tau}^{2}=2.42, \mathrm{chi}^{2}=100.18, \mathrm{df}=3,(\mathrm{P}<0.00001) ; \mathrm{I}^{2}=97 \%\right]$ was encountered among included trials. In the random effects model (SMD, -2.83 ; 95\% CI, $-4.38,-1.27$; $\mathrm{z}=3.56$; $\mathrm{P}=0.0004$; Figure 3) analysis, the use of Simethicone \pm $\mathrm{NAC}$ is associated with improved mucosal visibility score during OGD.

\section{Patients with good/excellent mucosal visibility}

Three RCTs (32-34) reported number of patients with good/excellent mucosal visibility and contributed to the combined calculations of this variable. There was no heterogeneity $\left[\mathrm{Tau}^{2}=0.00, \mathrm{chi}^{2}=1.82, \mathrm{df}=2,(\mathrm{P}=0.40)\right.$; $\left.\mathrm{I}^{2}=0 \%\right]$ among included trials. In the random effects model (OR, 0.43; 95\% CI, 0.28, 0.68; z=3.65; $\mathrm{P}=0.0003$; Figure 4) analysis, in the Simethicone \pm NAC group there were more patients with good/excellent mucosal visibility compared to no-Simethicone group.

\section{Discussion}

\section{Summary of main results}

The findings of current study on seven CRTs investigating 


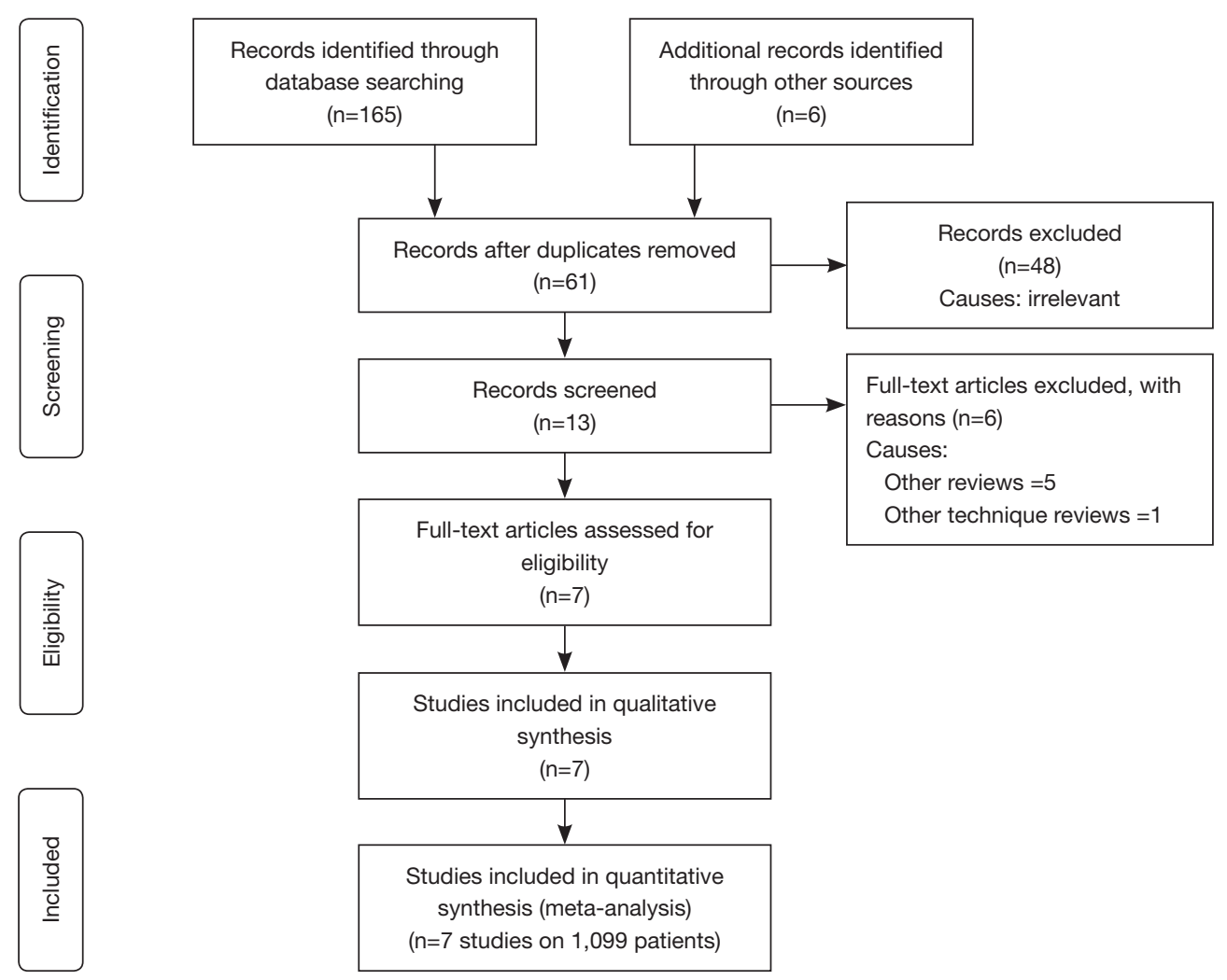

Figure 1 PRISMA flow diagram.

Table 1 Trials reporting adequate/poor visibility as mucosal visibility score

\begin{tabular}{lccccc}
\hline \multirow{2}{*}{ Studies } & \multicolumn{2}{c}{$\operatorname{Sim} \pm$ NAC group } & \multicolumn{2}{c}{ No Sim \pm NAC group } \\
\cline { 2 - 3 } \cline { 5 - 6 } & Total patients & Mean visibility score & & Total patients & Mean visibility score \\
\hline Asl et al. (28) & 110 & $6.30 \pm 1.69$ & 38 & $9.5 \pm 2.55$ \\
Basford et al. (29) & 41 & $1.45 \pm 0.09^{\star}$ & 81 & $2.13 \pm 0.11^{*}$ \\
Keeratichananont et al. (30) & 63 & $6.83 \pm 2.4$ & 58 & $11.05 \pm 2.6$ \\
Song et al. (31) & 27 & $5.78 \pm 1.65$ & 27 & $8.89 \pm 1.97$ \\
\hline
\end{tabular}

*, the standard deviation estimated from $\mathrm{P}$ value or range. Sim, Simethicone; NAC, N-acetyl cysteine.

Table 2 Trials reporting number of patients with adequate versus poor visibility

\begin{tabular}{lccccc}
\hline \multirow{2}{*}{ Studies } & \multicolumn{2}{c}{ Sim \pm NAC group } & & No Sim \pm NAC group \\
\cline { 2 - 3 } \cline { 5 - 6 } & Total patients & Patients achieving adequate visibility & & Total patients & Patients achieving adequate visibility \\
\hline Ahsan et al. (32) & 90 & $27 / 90$ & 83 & $48 / 83$ \\
Elvas et al. (33) & 199 & $1 / 199(100 \%)$ & 98 & $4 / 98(96 \%)$ \\
Monrroy et al. (34) & 138 & $57 / 138$ & 46 & $26 / 46$
\end{tabular}

Sim, Simethicone; NAC, N-acetyl cysteine. 
Simethicone +/- N-acetylcysteine for OGD to improve mucosal visualization

Patient or population: patients with OGD to improve mucosal visualization

Settings:

Intervention: Simethicone $+/-\mathrm{N}$-acetylcysteine

\begin{tabular}{|c|c|c|c|c|c|c|}
\hline \multirow[t]{3}{*}{ Outcomes } & \multicolumn{2}{|c|}{ Illustrative comparative risks ${ }^{*}(95 \% \mathrm{Cl})$} & \multirow{3}{*}{$\begin{array}{l}\text { Relative effect } \\
(95 \% \mathrm{Cl})\end{array}$} & \multirow{3}{*}{$\begin{array}{l}\text { No of Participants } \\
\text { (studies) }\end{array}$} & \multirow{3}{*}{$\begin{array}{l}\text { Quality of } \\
\text { the evidence } \\
\text { (GRADE) }\end{array}$} & \multirow[t]{3}{*}{ Comments } \\
\hline & Assumed risk & Corresponding risk & & & & \\
\hline & Control & $\begin{array}{l}\text { Simethicone +/- } \\
\mathrm{N} \text {-acetylcysteine }\end{array}$ & & & & \\
\hline \multirow{4}{*}{$\begin{array}{l}\text { Excellent/good } \\
\text { visibility } \\
\text { Odds ratio } \\
\text { Follow-up: mean } \\
1 \text { days }\end{array}$} & \multicolumn{2}{|c|}{ Study population } & \multirow{4}{*}{$\begin{array}{l}\text { OR } 0.43 \\
\text { (0.28 to } 0.68)\end{array}$} & \multirow[t]{4}{*}{654 (3 studies) } & \multirow{4}{*}{$\begin{array}{l}\oplus \oplus \oplus \oplus \\
\text { high }\end{array}$} & \\
\hline & $\begin{array}{l}322 \text { per } \\
1,000\end{array}$ & $\begin{array}{l}169 \text { per } 1,000 \\
\text { (117 to } 244)\end{array}$ & & & & \\
\hline & \multicolumn{2}{|l|}{ Moderate } & & & & \\
\hline & $\begin{array}{l}518 \text { per } \\
1,000\end{array}$ & $\begin{array}{l}316 \text { per } 1,000 \\
(231 \text { to } 422)\end{array}$ & & & & \\
\hline
\end{tabular}

${ }^{*}$ The basis for the assumed risk (e.g., the median control group risk across studies) is provided in footnotes. The corresponding risk (and its $95 \%$ confidence interval) is based on the assumed risk in the comparison group and the relative effect of the intervention (and its $95 \% \mathrm{Cl}$ ).

Cl: confidence interval; OR: odds ratio;

GRADE Working Group grades of evidence

High quality: Further research is very unlikely to change our confidence in the estimate of effect.

Moderate quality: Further research is likely to have an important impact on our confidence in the estimate of effect and may change the estimate.

Low quality: Further research is very likely to have an important impact on our confidence in the estimate of effect and is likely to change the estimate.

Very low quality: We are very uncertain about the estimate.

Simethicone +/- N-acetylcysteine for OGD to improve mucosal visualization

Patient or population: patients with OGD to improve mucosal visualization

Settings:

Intervention: Simethicone + /- N-acetylcysteine

\begin{tabular}{|c|c|c|c|c|c|c|}
\hline Outcomes & $\begin{array}{l}\text { Illustrative com } \\
\text { Assumed risk } \\
\text { Control }\end{array}$ & $\begin{array}{l}\text { Corresponding risk } \\
\text { Simethicone }+/- \\
\text { N-acetylcysteine }\end{array}$ & $\begin{array}{l}\text { Relative effect } \\
(95 \% \mathrm{Cl})\end{array}$ & $\begin{array}{l}\text { No of Participants } \\
\text { (studies) }\end{array}$ & $\begin{array}{l}\text { Quality of } \\
\text { the evidence } \\
\text { (GRADE) }\end{array}$ & Comments \\
\hline $\begin{array}{l}\text { Visibility score } \\
\text { Standardized mean } \\
\text { difference } \\
\text { Follow-up: mean } \\
1 \text { days }\end{array}$ & & $\begin{array}{l}\text { The mean visibility score } \\
\text { in the intervention groups } \\
\text { was } 2.83 \text { standard } \\
\text { deviations lower ( } 4.38 \text { to } \\
1.27 \text { lower) }\end{array}$ & & 445 (4 studies) & $\begin{array}{l}\oplus \oplus \oplus \oplus \\
\text { high }\end{array}$ & $\begin{array}{l}\text { SMD }-2.83 \\
(-4.38 \text { to }-1.27)\end{array}$ \\
\hline \multicolumn{7}{|c|}{$\begin{array}{l}\text { 'The basis for the assumed risk (e.g., the median control group risk across studies) is provided in footnotes. The corresponding risk (and it } \\
95 \% \text { confidence interval) is based on the assumed risk in the comparison group and the relative effect of the intervention (and its } 95 \% \mathrm{Cl} \text { ). }\end{array}$} \\
\hline \multicolumn{7}{|c|}{$\begin{array}{l}\text { GRADE Working Group grades of evidence } \\
\text { High quality: Further research is very unlikely to change our confidence in the estimate of effect. } \\
\text { Moderate quality: Further research is likely to have an important impact on our confidence in the estimate of effect and may change the } \\
\text { estimate. }\end{array}$} \\
\hline
\end{tabular}

Figure 2 GRADEPro summary of evidence. $\oplus$, level of evidence. 


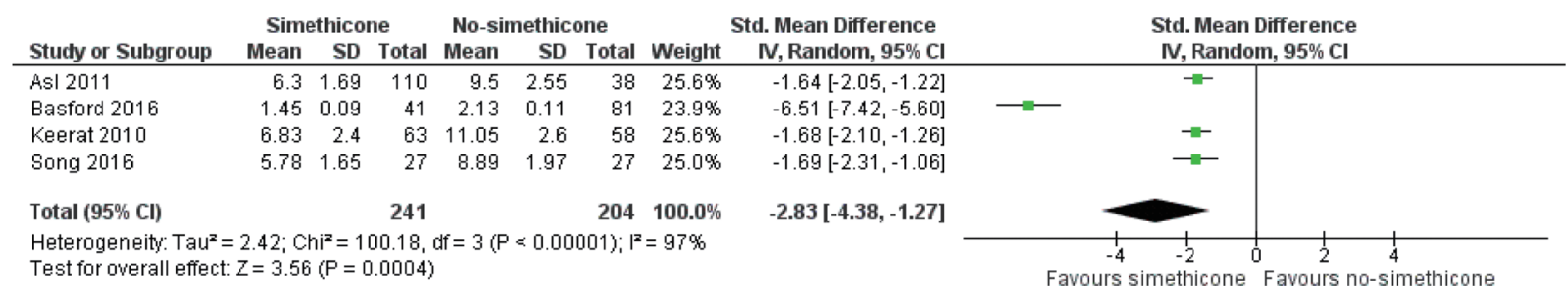

Figure 3 Forest plot for the studies reporting mucosal visibility score in patients undergoing OGD. Standardized mean difference is shown with $95 \%$ confidence intervals. OGD, oesophago-gastro-duodenoscopy.

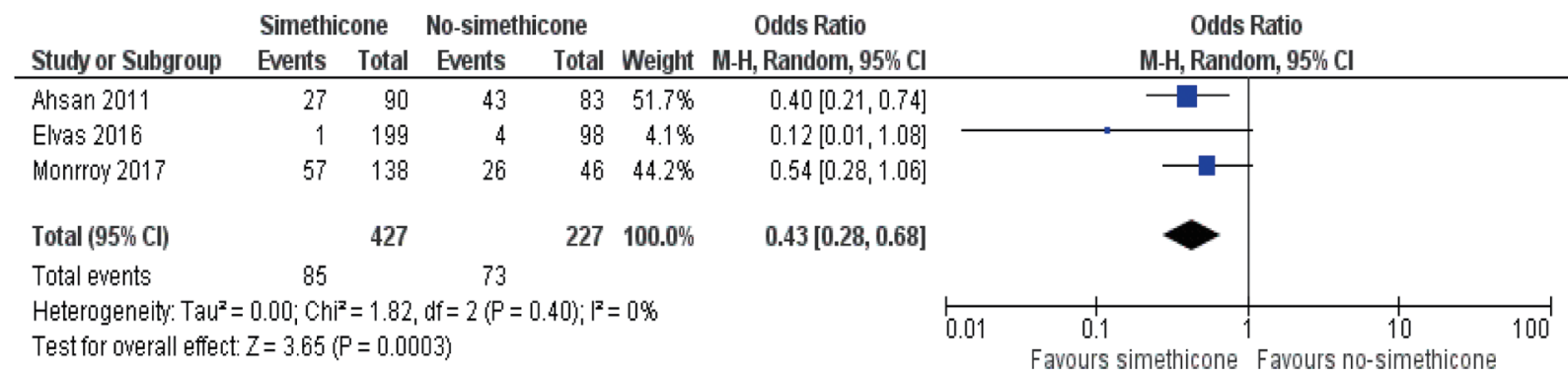

Figure 4 Forest plot for the studies reporting number of patients with good/excellent mucosal visibility in patients undergoing OGD. Odds ratio is shown with $95 \%$ confidence intervals. OGD, oesophago-gastro-duodenoscopy.

1,099 patients undergoing OGD for diagnostic indications successfully demonstrate that the pre-procedure oral administration of Simethicone \pm NAC improves mucosal visualization and mucosal visualization score.

\section{Application and completeness of evidence in this study}

The strict inclusion criterion was applied in the study selection for this review and it was restricted to the combined evaluation of published RCTs either reporting mucosal visibility score or number of patients with good/excellent mucosal visibility during OGD. Therefore, the resulting conclusions of this study are appropriate and applicable to the patients who require OGD to avoid missed diagnoses.

\section{Strength of the presented evidence}

Standard quality assessment tools were used to conduct current meta-analysis. The assessment of the included studies was performed using multi-dimensional pathways like the use of "risk of bias assessment" tool by the Cochrane Collaboration, Jadad and Chalmers et al. scoring systems; and tabulated presentation of summary evidence from the GRADE-pro tool recommended by the Cochrane Collaboration. Overall strength of evidence may be considered high as depicted in Figure 2.

\section{Potential biases in the review process}

The variable experience of the endoscopist, uses of various doses of Simethicone \pm NAC and use of different position techniques for OGD may have swayed the final outcomes. Lack of an agreed measuring tool to define the extent of mucosal visibility and various grades of mucosal visibility is also a significant flaw in include RCTs.

\section{Agreement and disagreement with other published evidence}

The resulting evidence form this meta-analysis is in concordance with previously published several studies $(15,28$ $37)$ and at least two systematic reviews (38,39). First systematic review (38) was published in 2011 but has limitations of analysing trials investigating the role of Simethicone \pm NAC in OGD, colonoscopy and capsule endoscopy. There were fewer trials on OGD alone at that time and therefore the reported evidence was weaker which needed validation. Second systematic review (39) was published in 2014 but the combined analysis was performed on all published trials regardless type of premedication (Simethicone, NAC, Pronase, water) used which resulted in biased outcome too. 


\section{Implications for practice and research}

Future implications of this study may be many. The development of a validated and an agreed mucosal visibility scoring tool is mandatory before running further trials to validate findings of current study and previously published trials. Various doses of Simethicone and comparison between Simethicone versus NAC, Pronase versus Simethicone and Pronase versus NAC may also need exploration before the routine use of Simethicone as premedication for OGD. Use of amount of water requiring for flushing to improve mucosal visualization may not considered an adequate measuring tool because of operator dependent variations and its ineffectiveness.

\section{Acknowledgements}

None.

\section{Footnote}

Conflicts of Interest: The abstract of this article has been accepted for presentation at the Annual General Meeting of the Associations of Surgeons of Great Britain and Ireland in Liverpool on $9^{\text {th }}-11^{\text {th }}$ May 2018. It will be published in the Supplement issue of the British fournal of Surgery.

\section{References}

1. Rex DK, Petrini JL, Baron TH, et al. Quality indicators for colonoscopy. Am J Gastroenterol 2006;101:873-85.

2. Raftopoulos SC, Segarajasingam DS, Burke V, et al. A cohort study of missed and new cancers after esophagogastroduodenoscopy. Am J Gastroenterol 2010;105:1292-7.

3. Khalil Q, Gopalswamy N, Agrawal S. Missed esophageal and gastric cancers after esophagogastroduodenoscopy in a midwestern military veteran population. South Med J 2014;107:225-8.

4. Telford JJ, Enns RA. Endoscopic missed rates of upper gastrointestinal cancers: parallels with colonoscopy. Am J Gastroenterol 2010;105:1298-300.

5. Yalamarthi S, Witherspoon $\mathrm{P}, \mathrm{McC}$ Cole D, et al. Missed diagnoses in patients with upper gastrointestinal cancers. Endoscopy 2004;36:874-9.

6. Hosokawa O, Hattori M, Douden K, et al. Difference in accuracy between gastroscopy and colonoscopy for detection of cancer. Hepatogastroenterology
2007;54:442-4.

7. Wei W, Ge ZZ, Lu H, et al. Purgative bowel cleansing combined with simethicone improves capsule endoscopy imaging. Am J Gastroenterol 2008;103:77-82.

8. Rokkas T, Papaxoinis K, Triantafyllou K, et al. Does purgative preparation influence the diagnostic yield of small bowel video capsule endoscopy?:A meta-analysis. Am J Gastroenterol 2009;104:219-27.

9. Tongprasert S, Sobhonslidsuk A, Rattanasiri S. Improving quality of colonoscopy by adding simethicone to sodium phosphate bowel preparation. World J Gastroenterol 2009;15:3032-7.

10. Yoo IK, Jeen YT, Kang SH, et al. Improving of bowel cleansing effect for polyethylene glycol with ascorbic acid using simethicone: A randomized controlled trial. Medicine (Baltimore) 2016;95:e4163.

11. Brecević L, Bosan-Kilibarda I, Strajnar F. Mechanism of antifoaming action of simethicone. J Appl Toxicol 1994;14:207-11.

12. Torrado G, García-Arieta A, de los Ríos F, et al. Quantitative determination of dimethicone in commercial tablets and capsules by Fourier transform infrared spectroscopy and antifoaming activity test. J Pharm Biomed Anal 1999;19:285-92.

13. Joshi KS, Baumann A, Jeelani SA, et al. Mechanism of bubble coalescence induced by surfactant covered antifoam particles. J Colloid Interface Sci 2009;339:446-53.

14. Kaplan MA, Prior MJ, Ash RR, et al. Loperamidesimethicone vs loperamide alone, simethicone alone, and placebo in the treatment of acute diarrhea with gas-related abdominal discomfort. A randomized controlled trial. Arch Fam Med 1999;8:243-8.

15. Neale JR, James S, Callaghan J, et al. Premedication with $\mathrm{N}$-acetylcysteine and simethicone improves mucosal visualization during gastroscopy: a randomized, controlled, endoscopist-blinded study. Eur J Gastroenterol Hepatol 2013;25:778-83.

16. Stomach cancer incidence statistics 2015 [updated 201505-15]. Available online: http://www.cancerresearchuk.org/ health-professional/cancer-statistics/statistics-by-cancertype/stomach-cancer/incidence

17. Callaghan JL, Neale JR, Boger PC, et al. Variation in preparation for gastroscopy: lessons towards safer and better outcomes. Frontline Gastroenterol 2016;7:187-90.

18. Jadad AR, Moore RA, Carroll D, et al. Assessing the quality of reports of randomized clinical trials: is blinding necessary? Control Clin Trials 1996;17:1-12.

19. Chalmers TC, Smith H, Blackburn B, et al. A method for 
assessing the quality of a randomized control trial. Control Clin Trials 1981;2:31-49.

20. Cochrane IMS. [Accessed on 10/03/2018]. Available online: http://ims.cochrane.org/revman/otherresources/ gradepro/download

21. Higgins JPT, Green S. editors. Cochrane Handbook for Systematic Reviews of Interventions. [Accessed on 10/03/2018]. Available online: http://www.cochranehandbook.org

22. Review Manager (RevMan) [Computer program]. Version 5.0. The Nordic Cochrane Centre, The Cochrane Collaboration: Copenhagen, 2008. Available online: http:// tech.cochrane.org/revman/download/windows64; accessed on $10 / 03 / 2018$

23. DerSimonian R, Laird N. Meta-analysis in clinical trials. Control Clin Trials 1986;7:177-88.

24. Demets DL. Methods for combining randomized clinical trials: strengths and limitations. Stat Med 1987;6:341-50.

25. Higgins JP, Thompson SG. Quantifying heterogeneity in a meta-analysis. Stat Med 2002;21:1539-58.

26. Egger M, Smith GD, Altman DG. Systematic reviews in healthcare. BMJ Publishing, London, 2006. Available online: http://eu.wiley.com/WileyCDA/WileyTitle/ productCd-072791488X.html; accessed on 10/03/2018.

27. Deeks JJ, Altman DG, Bradburn MJ. Statistical methods for examining heterogeneity and combining results from several studies in meta-analysis. In: Egger M, Smith GD, Altman DG. editors. Systemic reviews in health care: meta-analysis in context. 2 nd edn. London: BMJ Publication group, 2001:285-312.

28. Asl SM, Sivandzadeh GR. Efficacy of premedication with activated Dimethicone or $\mathrm{N}$-acetylcysteine in improving visibility during upper endoscopy. World J Gastroenterol 2011;17:4213-7.

29. Basford PJ, Brown J, Gadeke L, et al. A randomized controlled trial of pre-procedure simethicone and $\mathrm{N}$-acetylcysteine to improve mucosal visibility during gastroscopy - NICEVIS. Endosc Int Open 2016;4:E1197-E1202.

30. Keeratichananont S, Sobhonslidsuk A, Kitiyakara T, et al.

doi: 10.21037/tgh.2018.05.02

Cite this article as: Sajid MS, Rehman S, Chedgy F, Singh KK. Improving the mucosal visualization at gastroscopy: a systematic review and meta-analysis of randomized, controlled trials reporting the role of Simethicone $\pm \mathrm{N}$-acetylcysteine. Transl Gastroenterol Hepatol 2018;3:29.
The role of liquid simethicone in enhancing endoscopic visibility prior to esophagogastroduodenoscopy (EGD): A prospective, randomized, double-blinded, placebocontrolled trial. J Med Assoc Thai 2010;93:892-7.

31. Song M, Kwek AB, Law NM, et al. Efficacy of smallvolume simethicone given at least $30 \mathrm{~min}$ before gastroscopy. World J Gastrointest Pharmacol Ther 2016;7:572-8.

32. Ahsan M, Babaei L, Gholamrezaei A, et al. Simethicone for the Preparation before Esophagogastroduodenoscopy. Diagn Ther Endosc 2011;2011:484532.

33. Elvas L, Areia M, Brito D, et al. Premedication with simethicone and $\mathrm{N}$-acetylcysteine in improving visibility during upper endoscopy: a double-blind randomized trial. Endoscopy 2017;49:139-45.

34. Monrroy H, Vargas JI, Glasinovic E, et al. Use of $\mathrm{N}$-acetylcysteine plus simethicone to improve mucosal visibility during upper GI endoscopy: a double-blind, randomized controlled trial. Gastrointest Endosc 2018;87:986-93.

35. Wang C, Liu H, Wang X, et al. Benefit of a 360-degree horizontal turn following premedication with simethicone on image quality during gastroendoscopy: a randomized controlled trial. Int J Clin Exp Med 2015;8:4281-6.

36. Bertoni G, Gumina C, Conigliaro R, et al. Randomized placebo-controlled trial of oral liquid simethicone prior to upper gastrointestinal endoscopy. Endoscopy 1992;24:268-70.

37. Banerjee B, Parker J, Waits W, et al. Effectiveness of preprocedure simethicone drink in improving visibility during esophagogastroduodenoscopy: a double-blind, randomized study. J Clin Gastroenterol 1992;15:264-5.

38. Wu L, Cao Y, Liao C, et al. Systematic review and metaanalysis of randomized controlled trials of Simethicone for gastrointestinal endoscopic visibility. Scand J Gastroenterol 2011;46:227-35.

39. Chen HW, Hsu HC, Hsieh TY, et al. Pre-medication to improve esophagogastroduodenoscopic visibility: a metaanalysis and systemic review. Hepatogastroenterology 2014;61:1642-8. 